\title{
A Quantitative LitToral Classification System
}

\author{
By A. Brandt, J. Calman \\ and J.R. Rottier
}

\begin{abstract}
A GENERAL APPROACH for quantitative classification of littoral sites has been developed. The approach uses dimensionless parameters to describe the processes in a specific area of physics (e.g., ocean physics, meteorology, acoustics, etc.) and in a particular coastal geographic configuration (e.g., shelves, straits, enclosed seas, rivers, etc.). As a first application, a littoral classification system has been developed to describe the physical oceanographic processes on coastal continental shelves. This system incorporates four dimensionless parameters to describe the large-scale ocean features that characterize specific coastal regions: eddies, upwelling. currents, and stratification. Seven diverse worldwide sites have been compared using these classification parameters. illustrating their differences and similarities. This classification system is then used to address a specific coastal issue: the dispersion of a point discharge in the surface layer.

Events in both the civil and military sectors during recent years have resulted in increased interest in the littoral, including diverse and important topics such as the viability of coastal ecosystems, prediction of hurricane tracks. the effects of climate change on water levels, and sensor and weapon performance for naval operations in littoral waters (e.g., Davis VI, 1995: Warrick et al., 1996). To address these issues an understanding of the littoral ocean environment is needed. The littoral, however, presents additional complexities compared with the open ocean. because of the large space-time variability of the submesoscale physical, biological, and optical properties of the
\end{abstract}

A. Brandt, J. Calman. J.R. Rottier, The Johns Hopkins University Applied Physics Laboratory. Laurel, MD 20723. USA. water column and the site-specific nature of the coastal geometry and topography. As a result. littoral modeling and design efforts inherently tend to be site specific.

Nevertheless, littoral sites do have some attributes in common. A littoral classification scheme based on the parameters that describe the key physical processes would allow quantitative comparison among sites and for extrapolation of data and models to sites that have not been studied by identifying analogous sites where data are available. Such a classification scheme would also provide a basis for assessing the performance of naval systems [antisubmarine warfare (ASW) techniques, weapons. etc.] and for the design of data collection scenarios appropriate to sites that are not readily accessible.

To date. attempts to classify littoral areas have generally employed qualitative comparisons. The only published quantitative classification scheme was developed for estuaries. The initial classification of estuarine types was developed by Pritchard (1955, 1989), who classified estuaries into highly stratified, weakly stratified, and partially mixed categories. This was extended and made quantitative by Hansen and Rattray (1965) and Jay and Smith (1988), who used a two-parameter system derived from the theoretical relationships for the estuarine salt balance.

The classification framework presented herein follows the general philosophy employed in the development of the estuarine classification scheme. It utilizes the fundamental equations governing littoral processes as a basis for determining the classification parameters, appropriate to particular littoral configurations, i.e., coastal shelves, enclosed seas, straits, etc. As envisioned, this general approach could be used to derive a classification scheme for any class of littoral processes, i.e.. physical, acoustic, meteorological, etc.

\section{Littoral Classification-A Quantitative Approach}

Differences in geometry, topography, and the physical processes at littoral sites tend to make each site unique when observed at a sufficient level of detail. To identify the underlying similarities among sites, one must, in a sense. "step back" to a level of abstraction that allows the various sites to exhibit commonalities, while ignoring the details. The degree of abstraction, however, must not be too great or everything will tend to look the same (e.g., all coasts have a shelf break), and the classification would be of little use. Moreover, to be useful for more than just general statements of site similarities, the scheme must provide quantitative estimates of the characterizing parameters.

Based on these general requirements. there are three basic criteria that a viable classification scheme must meet:

1. The classification parameters must represent the key governing processes.

2 . The parameters must quantitatively parameterize these processes.

3 . The parameters must involve only readily available, site-specific data.

Identification of the governing processes is key to obtaining a useful classification scheme; however, there is no general procedure for identifying these parameters that will apply in all situations. For a specific type of coastal region and a specific class of physical processes, such as in the case of the estuarine classification, it is possible to use a well-defined system of equations to derive the appropriate quantitative parameters (dimensionless groups). For other more general situations, such as for classifying the physical oceanographic processes on coastal continental 
shelves (as discussed subsequently), the plethora of differing processes (i.e., tidal motions, upwelling, shelf break fronts, etc.) precludes the use of any one set of equations. Thus a more heuristic approach for the determination of the key processes is employed. It involves identification of the parameters that result from the forces driving the system. which in turn govern the more detailed (small-scale) phenomena. Additionally, if the scheme is to be useful in a practical sense, these parameters should depend only on data readily available from the current databases (criterion 3 listed previously).

There are a wide range of phenomena of potential interest in littoral areas, e.g., physical, acoustic, biological, atmospheric, etc., each of which encompass a range of dynamic processes. Also, there are many different types of coastal geographical configurations (CGC), shelves, straits, enclosed seas, rivers, etc.; each having its own characteristics and key parameters. It follows that a littoral classification scheme would have to be specific to each phenomenology-CGC combination. Development of a specific classification scheme thus involves initially choosing a phenomenology, CGC combination, from which the quantitative dimensionless groups can be identified. This process is schematically shown in Figure 1, left side. The general approach for further use of the classification scheme for specific applications is depicted on the right of Figure 1 and involves weighting of the classification parameters in a manner appropriate to the specific application. This general approach will be employed to derive a coastal shelf classification scheme in this paper.

\section{A Littoral Classification for Physical Processes on Coastal Continental Shelves}

Acknowledging the wide range of physical processes extant in coastal shelf regions (cf.. Csanady, 1982; Hsu, 1988), we adopt a heuristic approach to determine the appropriate classification parameters. The approach followed starts with identifying the driving forces and boundary conditions that drive the processes on the coastal shelf, as shown in Figure 2. Next the dynamic processes found in the coastal ocean are categorized as large-scale features that are

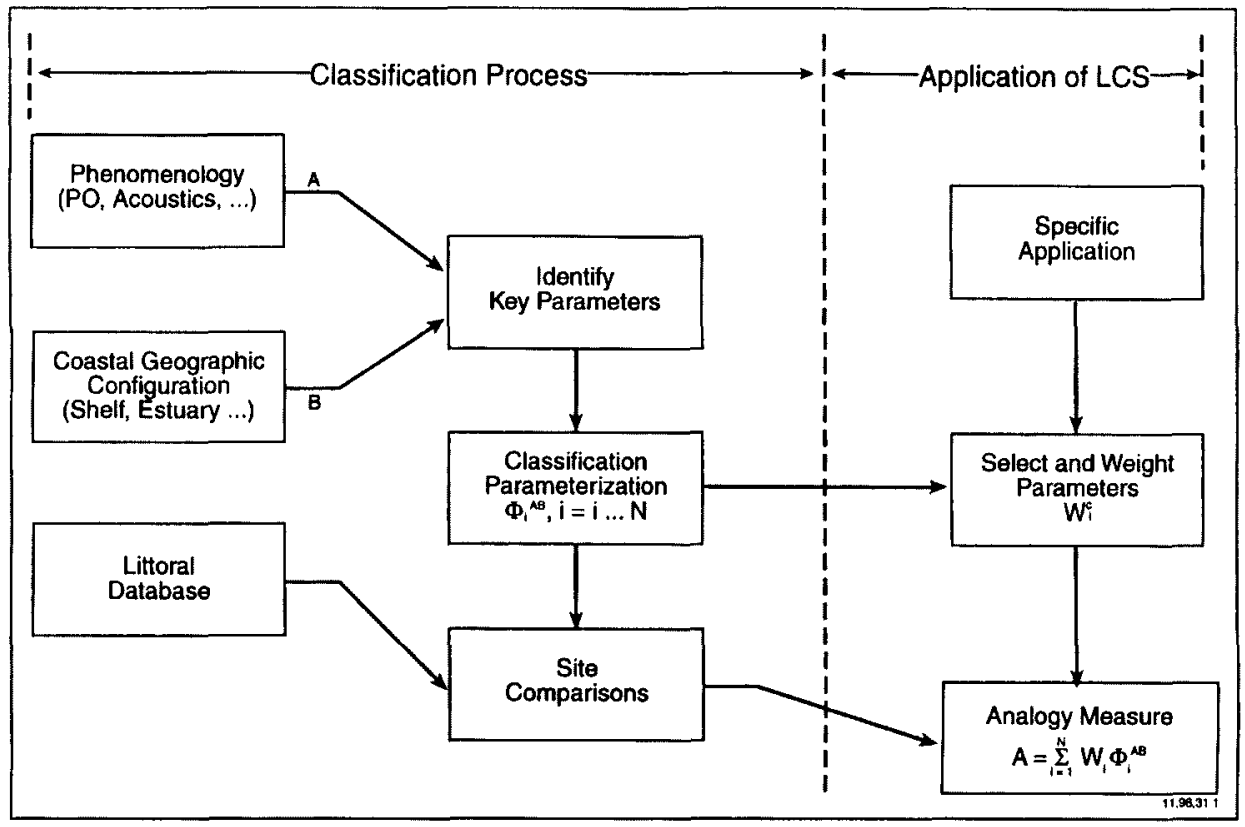

Fig. 1: Littoral classification approach. generally uniform over the whole of a specific coastal region and small-scale features that can be highly variable in time and/or space within that region. Our assessment of these features, based on a review and classification of the known physical processes (cf.. Phillips, 1977; Csanady, 1982, 1990; Pedlosky, 1987; Huyer, 1990), indicates that there are four primary, large-scale physical processes in the coastal/littoral ocean: eddies, upwelling. currents, and stratification (as indicated in Fig. 2). These large-scale features can be used to characterize the coastal region and provide the appropriate level of abstraction for our classification scheme. This admittedly heuristic assumption is the basis for our approach, the viability of which will be determined from the outcome, i.e., the ability to derive appropriate dimensionless parameters that allow site

\begin{tabular}{|c|c|c|}
\hline $\begin{array}{c}\text { Driving Forces \& } \\
\text { Boundary Conditions }\end{array}$ & Large Scale Features & $\begin{array}{l}\text { Local, Small-Scale } \\
\text { Processes (Partial List) }\end{array}$ \\
\hline $\begin{array}{l}\text { - Shelf width }\left(L_{s}\right) \text {, slope } \\
\text { - Inertial forcing }\left(R_{0}\right) \\
\text { - Wind stress }(\tau) \text {, friction } \\
\text { velocity }\left(\underline{u}_{A}\right) \\
\text { - Ocean circulation }\left(\underline{u}_{0}\right) \\
\text { - Tidal Forcing, } \\
\text { currents }\left(\underline{u}_{\tau}\right) \\
\text { - Surface heat flux } \\
\text { - River outflows } \\
\text { - Topography } \\
\text { - Coastal contour }\end{array}$ & $\begin{array}{l}\text { Coastal eddies, scale } \\
\text { Upwelling }\left(\mathrm{w}_{\mathrm{u}}\right) \\
\text { Coastal currents }(\underline{u}) \\
\text { Stratification }(\mathrm{N})\end{array}$ & $\begin{array}{l}\text { Cross-shelf currents } \\
\text { Coastal jets and filaments } \\
\text { Fronts: } \\
\text { - Shelf Break } \\
\text { - Tidal } \\
\text { Mixing: } \\
\text { - Surface Layer } \\
\text { - Internal } \\
\text { - Bottom BL } \\
\text { Internal waves } \\
\text { Optical clarity }\end{array}$ \\
\hline
\end{tabular}

Fig. 2: Coastal shelf processes. 
comparisons, particularly for specific applications.

In general, the nature and intensity of the small-scale processes are governed by the large-scale processes whose parameterization (developed subsequently) provides a basis for their assessment. As indicated in Figure 2, the boundary and driving forces are related to the largescale features and represent the basic parameters that can be calculated from the available databases. The two geological boundary conditions, topography and coastal contour (shoreline), do not enter directly but serve to define the boundaries of specific coastal shelf regions. The coastal shelf may have to be segmented to account for significant variations in the geological boundaries, as was necessary along the Korean coast in the site classification that follows.

To derive an appropriate parameterization for the four large-scale processes, we utilize the basic scaling relationships derivable from the accepted, classical oceanographic models. Consider first the coastal eddy scale. When the equations of motion for geophysical flows in a rotating frame are cast in dimensionless form, the key dimensionless parameter that arises is the Rossby number. Ro. Related to Ro is the Rossby radius of deformation, or simply the Rossby radius, $L_{R}$, that arises from the geostrophic balance (Gill, 1982: Pedlosky, 1987)

$$
\mathrm{L}_{\mathrm{R}}=\mathrm{c} /(2 \Omega \sin \phi)
$$

where $\mathrm{c}=\left(\mathrm{g}^{\prime} \mathrm{h}\right)^{\prime \prime 2}$ is an interfacial wave speed (assuming that there is a baroclinic. two-layer flow), $h$ is the thickness of the upper layer, $\mathrm{g}^{\prime} \equiv \mathrm{g} \Delta \rho / \rho_{i n}, \mathrm{~g}$ is the gravitational constant, $\Delta \rho$ is the density difference between the layers, $\rho_{0}$ is the mean, reference density, and $\phi$ is the latitude. The Rossby radius characterizes the scale of motion, induced by the earth's rotation, which for coastal regimes can be compared with the local horizontal scale. the shelf width. $\mathrm{L}_{\mathrm{S}}$ as

$$
\Phi_{1 .}=\mathrm{L}_{\mathrm{R}} / \mathrm{L}_{\mathrm{S}}
$$

This parameter indicates whether or not the large-scale motions are confined to the shelf region. It depends on the local shelf width and stratification as well as the latitude of the area of interest; $\Phi_{\mathrm{L}}<1$ indicating a wide shelf and $\Phi_{\mathrm{L}}>1$ indicating a narrow shelf. The coastal eddy scale, $\Phi_{L}$, will be used as the parameterization for coastal eddies for purposes of littoral

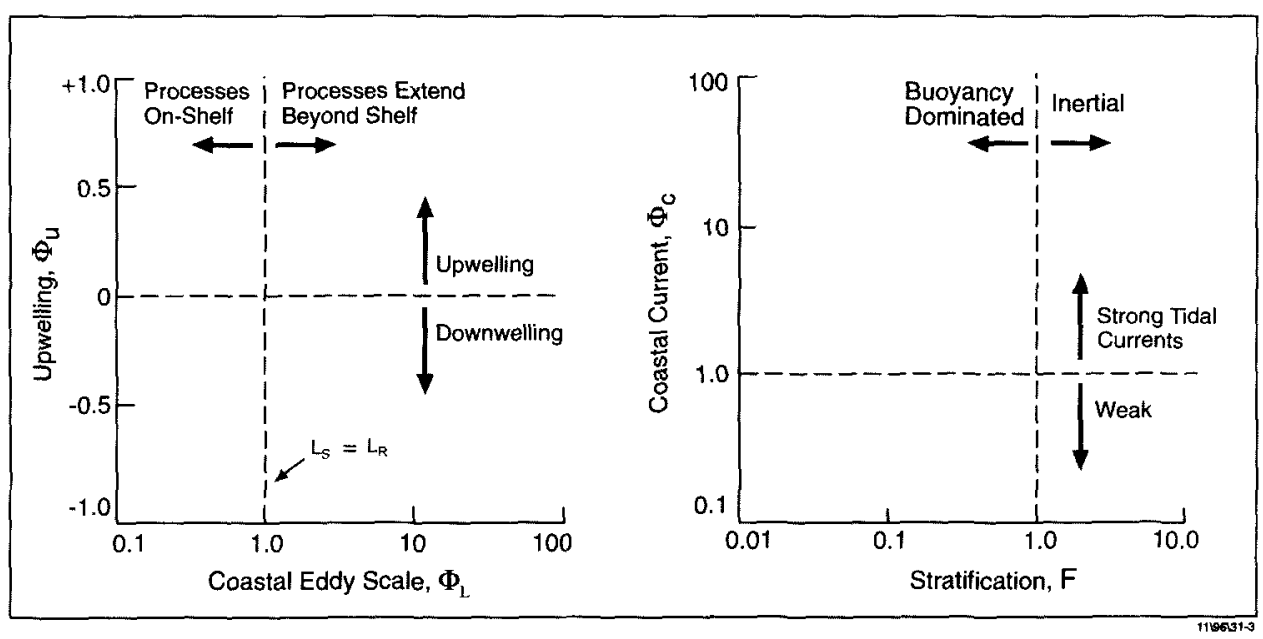

Fig. 3: Coastal shelf classification.

classification. This parameter (along with the other three, described as follows), is shown schematically in Figure 3, where the physical significance of the parameter ranges are also indicated.

Upwelling in coastal regions can result from several processes, including offshore Ekman transport resulting from wind stress and Coriolis acceleration, density discontinuities at the shelf break front, etc. (Huyer, 1990). To parameterize upwelling for this classification scheme, we utilize the simple, two-layer upwelling solution derived by Gill (1982), for the case of two-dimensional (no variation in the along-shore direction) baroclinic flow due to wind forcing. Gill's solution yields time-dependent relationships for the upper layer off-shore current speed, the interfacial depth, and the steady along-shore current speed. For the present application, we chose as a metric for the degree of upwelling the rate of change of the interfacial depth at the coast (the maximum value). i.e., the vertical upwelling velocity

$$
\mathrm{W}_{\mathrm{u}}=\mathrm{dh} / \mathrm{dt}=\tau / \rho_{0}\left(\mathrm{~g}^{\prime} \mathrm{h}\right)^{1 / 2}=\left(\tau / \rho_{0}\right) \mathrm{c}
$$

where $\tau$ is the along-shore surface wind stress. Using the conventional representation for $\tau$ in terms of the friction velocity, u*

$$
\left|\tau / \rho_{0}\right|=\mathrm{u}_{*}{ }^{2}=\mathrm{C}_{\mathrm{D}}\left|\mathrm{U}_{10}\right| \mathrm{U}_{10}
$$

where $U_{10}$ is the surface wind speed, conventionally measured at the 10 -m height, and $C_{D}$ is the drag coefficient taken as constant at the typical value of $C_{D}=$ 0.001 (Geernaert, 1990). The ratio of the upwelling velocity to the interfacial wave speed, c, that is characteristic of the twolayer geometry, yields the littoral upwelling parameter

$$
\Phi_{\mathrm{U}}=\mathrm{u}_{*}^{2} / \mathrm{c}^{2}
$$

$\Phi_{\mathrm{U}}$ serves as an indicator of the degree of upwelling that can be expected at a particular site as determined from the stratification (through c) and the wind speed and direction, $\mathrm{U}_{10}$. Upwelling versus downwelling conditions are determined from the direction of $\mathrm{U}_{10}$ and the coastal orientation, i.e., a northward wind on an east coast in the northern hemisphere will cause upwelling due to Ekman transport (Gill, 1982).

The third parameter is related to the along-shore coastal current. Tidal effects impose a variable, periodic current, $U_{T}$, that adds to the mean current, $U$, resulting from the wind stress and large-scale (deep water) circulation patterns. If $\mathrm{U}_{\mathrm{T}}$ is taken as the maximum tidal current over a tidal cycle, then the ratio

$$
\Phi_{\mathrm{C}}=\mathrm{U}_{\mathrm{T}} / \mathrm{U}
$$

indicates the relative contributions of the short-term ( $\sim$ semidiurnal) tidal flows and the long-term (e.g.. monthly average) coastal currents.

To represent the fourth parameter, the stratification, we use a bulk Froude number defined as

$$
\mathrm{F}=\Delta \mathrm{U} / \mathrm{N} \mathrm{h}_{\mathrm{i}}
$$

where $\Delta U$ is the difference between the upper and lower layer current speeds, and $h_{1}$ is the thickness of the interface between the upper and lower layers and 


$$
\begin{aligned}
\mathrm{N} & =\left(-\mathrm{g} \Delta \rho / \rho_{0} \Delta \mathrm{z}\right)^{1 / 2} \\
& =\left(-\mathrm{g}^{\prime} / \mathrm{h}_{\mathrm{i}}\right)^{1 / 2}
\end{aligned}
$$

is the buoyancy frequency. The Froude number results from the equations of motion for a stratified flow as the dimensionless parameter that represents the balance between the inertial and buoyancy forces (cf., Phillips, 1977). The stratification in most coastal regions can be reasonably represented as a two-layer system, so that $\mathrm{F}$ represents the degree to which the water column is stratified. Large values of $\mathrm{F}$ indicate that inertial forces (shear) dominates over buoyancy and that the stratification is weak, as is typical in the winter in the coastal ocean. Conversely small F indicates large buoyancy forces, i.e., strong stratification typical of summer conditions.

Figure 3 illustrates the significance of the four parameters that characterize the physical processes on coastal shelf regions: $\Phi_{\mathrm{L}}, \Phi_{\mathrm{U}}, \Phi_{\mathrm{C}}$, and F. These four parameters are mutually independent so the pairing of the parameters as shown in Figure 3 is arbitrary. The numerical scales for each of the parameters shown in Figure 3 represent the ranges anticipated for worldwide coastal shelf regions.

\section{Coastal Shelf Comparisons}

The four classification parameters can be used to represent the key coastal shelf processes. The quantities necessary to compute values for each of these parameters at specific sites are readily obtainable from data base compilations and the research literature, although they may be hard to obtain for certain remote or "protected" sites. In general, all the necessary parameters (such as the interface thickness, $h_{i}$ ) may not be directly specified in the available databases; however, they can be computed from the available data [e.g., $h_{\mathrm{i}}$ can be determined from standard conductivity, temperature, depth (CTD) profiles].

To illustrate the coastal shelf classification, data from seven sites have been collected and used to compute values of the four classification parameters. The locations of these sites are shown in Figure 4. Data for two U.S. sites, California and Gulf of Alaska, are available on a monthly average basis, whereas for the Washington State and foreign sites, only seasonally averaged data were readily available. (Data sources used include
Landry and Hickey, 1989; Thomson, 1981; Oceanographic Atlas of Korean Waters, 1987; Master Oceanography Observations Data Set, 1994; U.S. Navy Marine Climatic Atlas of the World, 1977; Tide Tables 1994, Central and Western Pacific Ocean and Indian Ocean, 1993; Lenz, 1995; Lenz and Chapman, 1989; S. Tarbell, 1995.)

Figure 5 shows the data from these seven sites in the form of classification diagrams. From these diagrams we can make several general observations regarding these sites. First, it is apparent from the values of the stratification parameter (Fig. 5b) that all of these coastal sites are influenced by stratification, i.e., $F<1$. The strongest effects of stratification were found to occur in the months of June and August at the Alaska and CODE (Southern California) sites, respectively. (Note that the seasonal averages for the foreign sites may obscure some of the stronger effects.) Weak stratification is indicated for the winter in the Korea-East 1 coastal segment and for all but the summer months at the Yellow Sea site. The latter is to be expected as this region is rather shallow, having a very wide shelf, as can be seen from the value of the coastal eddy/shelf width parameter, $\Phi_{\mathrm{L}}$, Figure 5a. The Yellow Sea (effectively a very wide shelf) also has a significantly larger coastal current parameter value as compared with the other sites, due to the strong, local tidal forcing. The Korea-East 2 eddy/shelf parameter also stands out from the others. Regarding upwelling, generally all sites indicate weak and variable up/downwelling, with exceptions of the strong upwelling in winter in the Yellow Sea and strong downwelling in winter at Korea-East 1.

An extensive error analysis was performed using the Alaska coastal data, because it is the most complete and thus provides the most accurate measure of the actual errors that can be expected at each of the sites. Errors in each of the four classification parameters were computed using values of the standard error of the monthly means of each of the database derived quantities and therefore represent the accuracies to which the parameters are representative of the monthly average conditions. These values are shown in Figure 5, as error bars, and can be seen to be sufficient to allow site comparisons and to distinguish seasonal variations when they are significant. Error estimates based on the Alaska data have also been computed for the derived parameters in the application of the littoral classification discussed in the following section.

In sum, the classification parameter space provides an indication of how these sites would respond to the physical forcing mechanisms and how they compare with each other. Site comparisons for a

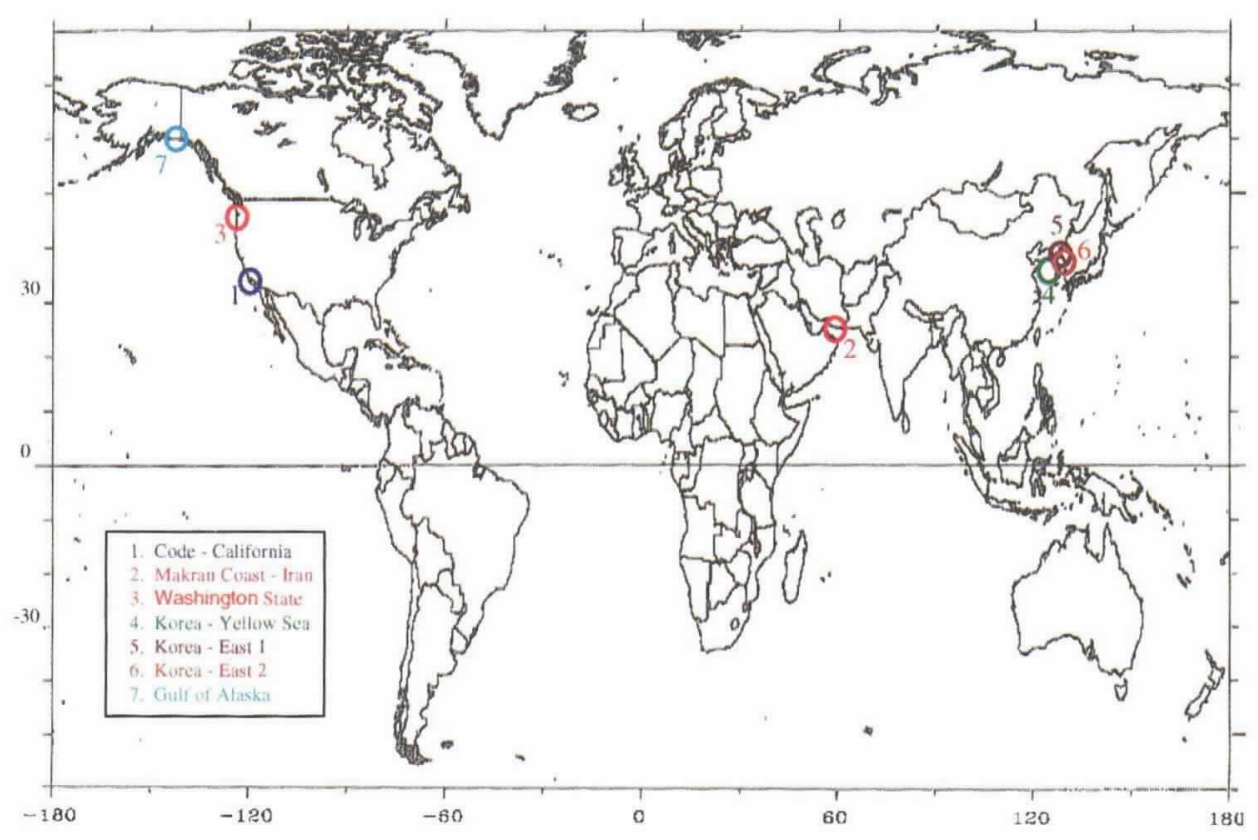

Fig. 4: Littoral sites investigated. 
specific application, illustrated in the following section, will use these classification parameters. Additional details of the derivations, especially for the following applications, are given in Brandt et al. (1997).

\section{Application of the Littoral Classification System}

To illustrate the utility of the littoral classification system, a specific coastal issue has been investigated: the dispersion of a point discharge in coastal waters.

Consider a relatively simple analysis of the dispersion of a point discharge (such as a toxic waste) in the surface layer off the coast. The concentration of discharged material at a specified time, $\mathrm{C}(\Delta \mathrm{t})$, is directly related to the volume over which the material has spread during the time interval, $\Delta \mathrm{t}$, since the initial release. In terms of the average along-shore and cross-shore coastal currents, $U$ and $\mathrm{V}$, respectively, and the vertical depth of mixing, $d$

$$
\mathrm{C}(\Delta \mathrm{t}) \propto \mathrm{U} \Delta \mathrm{t} \cdot \mathrm{V} \Delta \mathrm{t} \cdot \mathrm{d}
$$

In coastal waters the upper layer will generally be well mixed over short time periods (due primarily to wind-induced mixing) so that it is reasonable to assume that the discharged material will quickly fill the upper mixed layer, h, and that further vertical mixing will result from turbulent entrainment (cf., Csanady, 1990). Extensive studies of turbulent entrainment in stratified fluids, in the laboratory and the ocean (Fernando, 1991), indicate that the entrainment coefficient, defined as the vertical velocity of the interface between the mixed layer and the stratified layer, $\mathrm{u}_{\mathrm{e}}$, scales inversely with the bulk Richardson number, which is directly related to the Froude number (Eq. 7), as $\mathrm{u}_{\mathrm{c}}=0.002\left(\mathrm{~h}_{\mathrm{i}} / \mathrm{h}\right) \mathrm{F}^{2} \Delta \mathrm{U}$. Expressing the depth of mixing as the sum of the mixed layer depth and the depth of entrainment, $\mathrm{d}=\mathrm{h}+\mathrm{u}_{\mathrm{e}} \Delta \mathrm{t}$, and noting that the cross-shore velocity is generally highly variable and significantly less than the along-shore component (e.g., Kosro, 1987), we can approximate $\mathrm{V} \cong$ $0.1 \mathrm{U}$, so that

$$
\begin{aligned}
& \mathrm{C}(\Delta \mathrm{t}) \propto 0.1 \mathrm{U}^{2} \Delta \mathrm{t}^{2} . \\
& {\left[\mathrm{h}+0.002\left(\mathrm{~h}_{\mathrm{i}} / \mathrm{h}\right) \mathrm{F}^{2} \Delta \mathrm{U} \Delta \mathrm{t}\right] }
\end{aligned}
$$

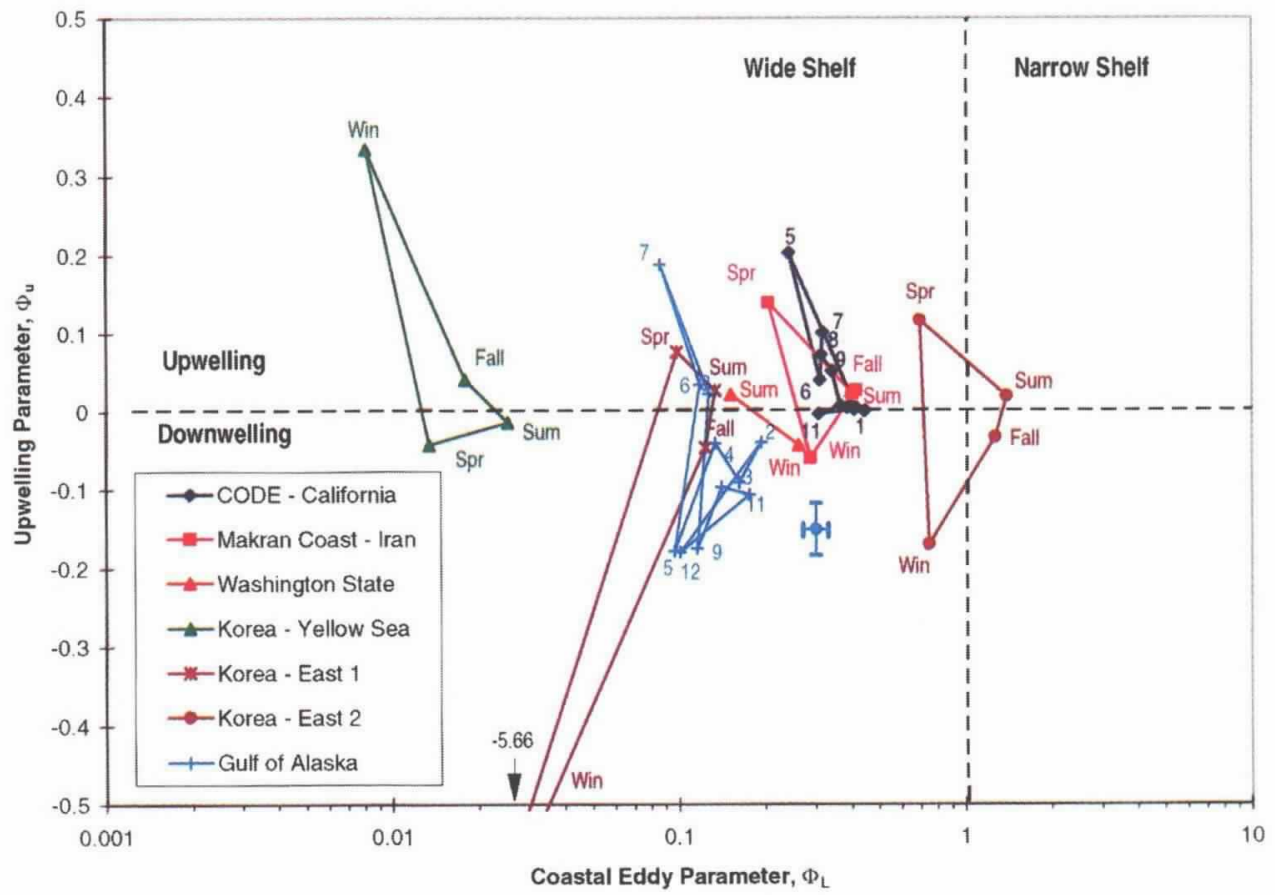

A

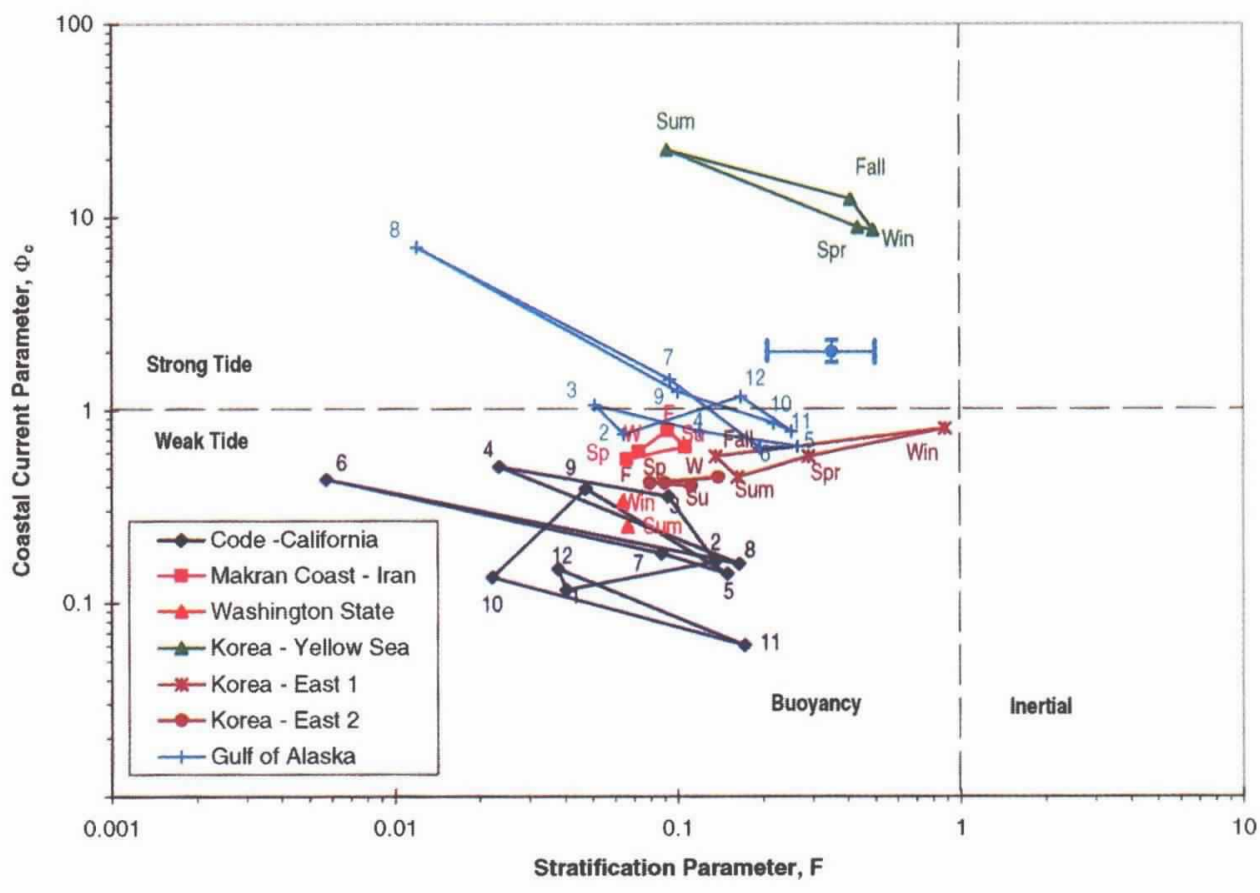

B

Fig. 5: Coastal shelf site comparison: (a) coastal upwelling and eddy parameters, (b) coastal current and stratification parameters.

To compare the dispersion at various coastal sites, it should be noted that all the quantities required for evaluation of equation (10) are already contained in the classification parameters, Figure 5, or in the data used to derive them. To compare sites it is instructive to separate the hori- zontal and vertical components of dispersion in equation (10), as

$$
\begin{aligned}
& \mathrm{C}_{1}=0.1 \mathrm{U}^{2} \Delta \mathrm{t}^{2} \\
& \mathrm{C}_{2}=\mathrm{h}+0.002\left(\mathrm{~h}_{\mathrm{i}} / \mathrm{h}\right) \mathrm{F}^{2} \Delta \mathrm{U} \Delta \mathrm{t}
\end{aligned}
$$


The values of these two parameters, for each of the seven sites, are shown in Figure 6 (contours of constant volume are indicated by the dotted lines).

The dispersion at some sites does not vary appreciably over the year, as for example, at the CODE and Korea-East 2 sites (Fig. 6). The Washington State, Makran Coast, and Korea-East 1 sites appear to have similar dispersion properties. This would allow for a reasonable extrapolation of observations at the Washington State site to the less accessible Makran Coast and Korea-East 1 locations. Dispersion in the shallow Yellow Sea varies widely with season and, as expected, is dominated by horizontal spreading. The high seasonal variations in the dispersion at the Gulf of Alaska coastal site results from the considerable variation in the winds. With observations such as these it would be possible, for example, to estimate the spread of toxic chemical or biological agents at sites of strategic interest based on measurements in more readily accessible areas.

\section{Summary}

A technique for quantitative classification of littoral sites has been developed based on the dimensionless parameters derived from the governing equations for specific physical processes and coastal geographical configurations. The scheme has been used to describe the physical

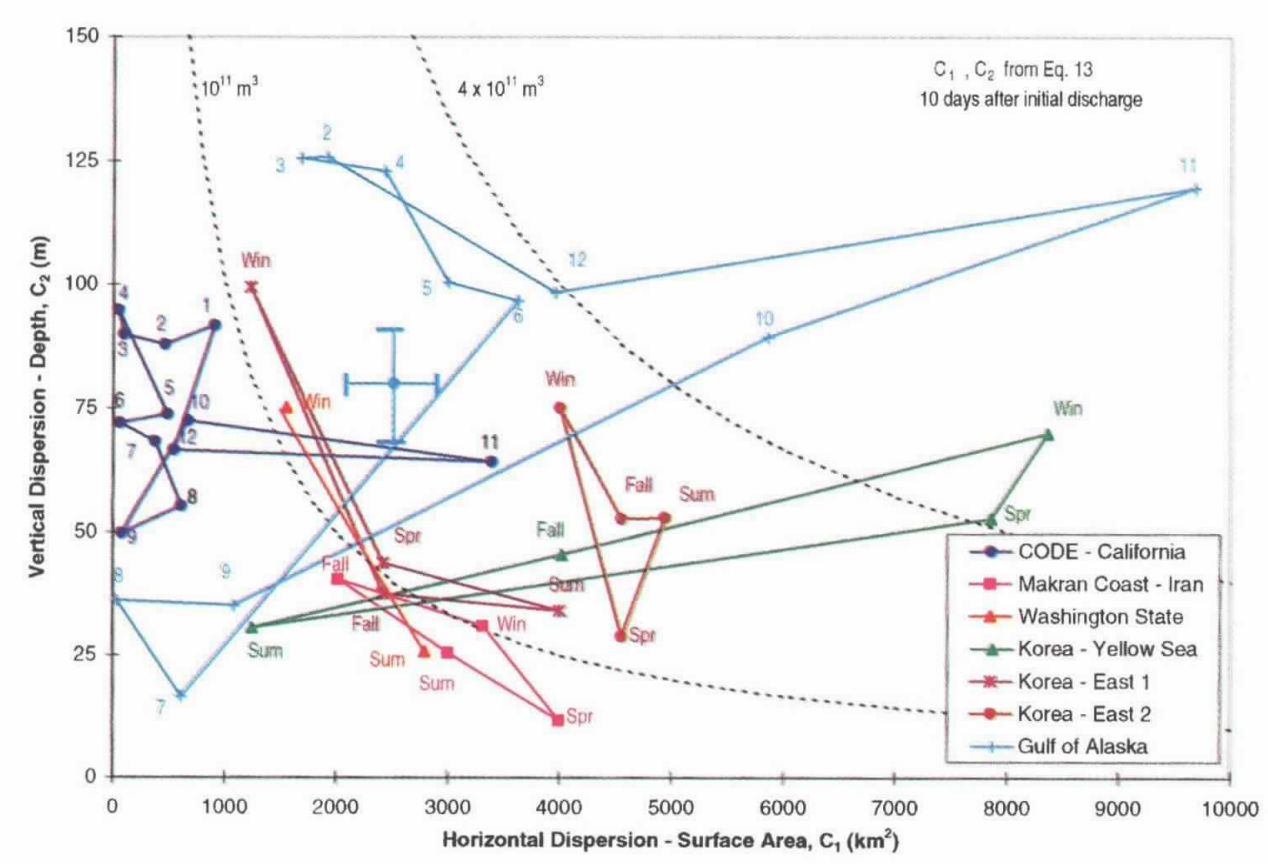

Fig. 6: Dispersion of a point discharge in the coastal ocean.

oceanographic processes on coastal continental shelves resulting in the definition of four dimensionless parameters to represent the large-scale features of coastal regions: eddies, upwelling, currents, and stratification. The processes at seven diverse, worldwide sites have been compared using these parameters. To illustrate the use of the littoral classification system, the coastal shelf classification parameters were used to investigate the dispersion of a point discharge in the surface layer. It was seen that some sites do in fact have similar characteristics, thus allowing extrapolation of information from studied, accessible sites to others of strategic or environmental interest that may not be readily accessible.

The general littoral classification approach could be applied to other areas of interest, such as meteorological and acoustic processes relevant to naval, defense, and civil issues. By identifying analogous sites, data and models could be extrapolated from sites that have been studied to sites that are not generally accessible, providing a basis for assessing, for example, the performance of naval weapon or surveillance systems, coastal radar propagation models, and the environmental impact of accidental or intentional releases.

Current efforts are focused on obtaining data from additional sites for the physical oceanographic-coastal shelf classification, the development of a classification scheme for near-shore (beach) processes, acoustic propagation in littoral waters, and the use of the general classification framework for additional, practical applications.

\section{Acknowledgements}

We thank L.J. Firzzell-Makowski and J.L. Hanson for their careful and constructive review of the manuscript. This effort has been supported by The Office of the Oceanographer of the Navy/Naval Research Laboratory, Tactical Oceanographic Monitoring System Program (K.M. Ferer), Contract SPAWAR N00039-91-C0001; The Office of Naval Research, Tactical Environmental Support Program (E. Hashimoto), Coastal Sciences Program (T.H. Kinder), Contract SPAWAR N00039-95-C0002; and Ocean Executive Agent, Defense Modelling and Simulation Office (D.W. Blake) Contract N0024-98-D-8124.

\section{References}

Brandt, A., J. Calman, and J.R. Rottier, 1997: A Quantitative Littoral Classification System. Johns Hopkins Univ. Applied Physics Lab. Report STD-B-0077, 27 pp.

Csanady, G.T., 1982: Circulation in the Coastal Ocean. Reidel, 279 pp.

1990: Mixing in coastal regions. In: Ocean Engineering Science, The Sea, vol. 9A. B. Le Mehaute and D.M. Hanes, eds. Wiley, New York, 593-629.

Davis, VI, G.W., 1995: Naval oceanography for the future. Sea Technology, 36, 13-21.

Fernando, H.J.S., 1991: Turbulent mixing in stratified fluids. Annu. Rev. Fluid Mech., 23, 455-493.

Gill, A.E., 1982: Atmosphere-Ocean Dynamics. Academic Press, New York, 662 pp.

Geernaert, G.L., 1990: Bulk parametrization for the wind stress and heat fluxes. In: Surface Waves and Fluxes, vol. 1. Current Theory. G.L. Geernaert and W.J. Plant, eds. Kluwer Academic Press, 91-172.

Hansen, D.V. and M. Rattray, Jr., 1965: Gravitational circulation in straits and estuaries. $J$. Mar. Res., 23, 104-122.

Hsu, S.A., 1988: Coastal Meteorology. Academic Press, New York, 260 pp.

Huyer, A., 1990: Shelf circulation. In: Ocean Engineering Science, The Sea, vol. 9A. B. Le Mehaute and D.M. Hanes, eds. Wiley, New York, 423-466.

Jay, D.A. and J.D. Smith, 1988: Residual circulation in and classification of shallow, stratified estuaries. In: Physical Processes in Estuaries. J. Dronkers and W. van Leussen, eds. Springer-Verlag, New York, 21-41.

Kosro, P.M., 1987: Structure of the coastal current field off northern California during the coastal ocean dynamics experiment. J. Geophys. Res., 92, 1637-1654.

Landry, M.R. and B.M. Hickey, 1989: Coastal Oceanography of Washington and Oregon. Elsevier Oceanography Series, vol. 47.

Lenz, S.J., 1995: Personal communication of CODE data. 
and D.C. Chapman, 1989: Seasonal differences in the current and temperature variability over the northern California shelf during the coastal ocean dynamics experiment. J. Geophys. Res., 94, 12571 12592.

Master Oceanography Observations Data Set, 1994: US Naval Oceanographic Office.

Oceanographic Atlas of Korean Waters, 1987: vol. 1, Yellow Sea, Korea Ocean Research and Development Institute.

Pediosky, J.. 1987: Geophysical Fluid Dynamics, 2nd edition. Springer-Verlag. New York, $710 \mathrm{pp}$.

Phillips. O.M.. 1977: The Dynamics of the Upper
Ocean, 2nd edition. Cambridge Univ. Press. $336 \mathrm{pp}$.

Pritchard. D.W.. 1955: Estuarine circulation patterns. Proc. Amer. Soc. Ciril Eng., 81, (717), 1-11. 1989: Estuarine classification--a help or a hindrance. In: Estuarine Circulation. B.J. Neilson, A. Kuo, and J. Brubaker, eds. Humana Press, Clifton. NJ, 1-38.

Tarbell. S. 1995: Personal Communication, coastal current meter data.

Thomson. R.E., 1981: Oceanography of the British Columbia Coast. Canadian Special Publication of fisheries and Aquatic Sciences. vol. 56.
Tide Tables 1994. Central and Westem Pacific Ocean and Indian Ocean, 1993: NOAA.

U.S. Naly Marine Climatic Atlas of the World. 1977: vol. 2, North Pacific Ocean. NAVAIR 50-1c-529.

Warrick. R.A., C. Le Provost. M.F. Meier, J. Oerlemans and P.L. Woodworth, 1996: Changes in sea level. In: Climute Change 1995, The Science of Climate Changt. J.T. Houghton. L. G. Meira Filho, B.A. Callander, N. Harris. A. Kattenberg and K. Maskell eds., Intergovernment Panel on Climate Change, Cambridge Univ. Press. $359-455$. 